\title{
Life after Domestic Homicide: Examining the Psychosocial Implications on Children-Survivor
}

\begin{abstract}
Although the problem of domestic violence has received considerable attention, the study of domestic homicide is relatively recent and limited to precipitating conditions or the act itself. Most of the literature on familicide focuses on the personality characteristics of the victim and perpetrator or tries to answer the question, "How did the death happen?" Little notice, however, has been given to the children of the victim and offender who, in the midst of their loss and extreme suffering, inherit the fallout from the death of one parent, and incarceration of the other. The study therefore explored the psychosocial implications of parental absence on account of death and incarceration on surviving children. Qualitative data were obtained from 18 convicted and awaiting trial inmates for spousal homicide in three selected prisons in Lagos state, key informant interviews (KII) with four officials of Office of Public Defenders (OPD), three officials of Directorate of Public Prosecutions (DPP) and two child psychologists. Surviving children of domestic homicide suffer massive upheaval, psychiatric disturbance, ill health, financial difficulties, ostracism, scars from witnessing the domestic violence that preceded the murder and the propensity for future intrafamilial violence. The study concludes that direct and indirect exposure to domestic violence and homicide is negatively associated with children's emotional, behavioural and developmental well-being. Hence, welfare of such children which should include therapy, relief of suffering, resolution of trauma symptoms, provision of supportive environment and clarification of cognitive or emotional distortions about the homicide should be incorporated in the prosecution process by relevant agencies.
\end{abstract}

Keywords: Children-Survivor, Domestic homicide, Psychosocial implications, Spousal homicide.

\section{Introduction}

Domestic violence and domestic homicide has come to represent major public health challenges and a key subject of criminological discourse in Nigeria, in particular, and the world in general. It is adjudged to be the most extreme form of domestic violence and one of the most common types of homicide in the world (Harlon, Brook, Demery, \& Cunningham, 2016). In Nigeria, the occurrences of domestic homicide appear to be on the increase despite the unavailability of reliable statistics. Without doubt, news reportage on spousal killing has reached an all-time high within the last two years in the country (Ifeanyichukwu et al., 2017; The Guardian, 2017). This trend has been confirmed by the office of the Directorate of Public Prosecution of Lagos State who remarked that women in the country are now six times more at risk of being murdered by their spouse than by a stranger. According to a senior officer of the directorate, in the first and second quarter of 2017 alone, there had been 13 cases of spousal homicide treated by the directorate. Meanwhile, Shija (2014) reported that an average of 300-350 women are killed by their husbands or boyfriends in Nigeria annually.

The interest of the criminal justice system and social welfare literature have been firmly positioned on what becomes of the survival and growth of children who are products of families that experienced domestic homicide. This is premised on the high impact that might trail the loss of a parent to domestic violence and the ensuing incarceration of the other parent for murder. Many of these children may already have the scars from witnessing the domestic violence that likely precedes the murder. They may observe the actual event, or their 
exposure may be more indirect, such as hearing violent encounters or later witnessing the results from a violent exchange. Both direct and indirect exposure to domestic violence is negatively associated with children's emotional, behavioural and developmental well-being (Godbout, Dutton, Lussier, \& Sabourin, 2009).

Recently, there have been an increasing body of evidence that describes the deleterious effects of exposure to domestic violence can have on the health, cognitive functioning and emotional well-being of children (Emery et al., 2011; Robbins et al., 2012; Harlon et al., 2016). As a matter of fact, the age of a child and stage of development can be an important determinant for what those consequences may be (Danies, Evans, \& DiLillo, 2016). For example, children who are within the primary school age and younger should ideally be learning to think in egocentric ways, begin the process of gender identification, develop language skills, and explore a moral schema. For children that are within this age, exposure to violence has been established as a positive correlate of disrupted developmental milestones such as language development, toilet training, and motor-skills acquisition (Schaefer, 2011). In addition to disrupted development, exposure to domestic violence is positively associated with reduced empathy and prosocial behaviours, poorer communication skills, and increased behaviours that undermine the development of a social network (Godbout et al., 2009).

Children that are of older age who are exposed to domestic violence are vulnerable to complex emotional and identity problems (Naughton, O'Donnell, \& Muldoon, 2017). This is due to the fact that they take social, gender, and behavioural cues from their adult role-models. For example, they are at risk of developing stereo-typed notions of gender, e.g. women are victims and men are perpetrators of domestic violence. Although peer identification is considered a key developmental task of adolescence, exposure to domestic violence may promote behaviours, which inhibit membership in a peer group. For example, several reports link exposure to domestic violence to aggressive behaviour, conduct problems, depression, anxiety, low self-esteem, and impaired social competencies. Empirical studies have pointed out that there is variability in the impact of domestic homicide on children (Harlon et al., 2016; Loius \& Johnson, 2017). It was asserted that the variability is hinged on the level of proximity of the child to the event. Although it is common for children who experience domestic violence to suffer post-traumatic stress syndrome (PTSD), physical health problems including psychosomatic concerns, and sleep disturbances, they are more often reported in children who witnessed the murder. The reaction of children to such experience may also vary based on their age. For example, younger children may start wetting the bed whereas older children may show an obsessive fascination with guns and violence (Naughton et al., 2017). Many have distressing nightmares and flashbulb memories of their parent's mutilated body including images and sounds of the incident.
Though there has been a considerable amount of research that focused on children's experience of domestic violence (Richards, 2011; Danies, Evans, \& DiLillo, 2016; Loius \& Johnson, 2017), little is known about what happens to these children in the aftermath of the murder of a parent and the incarceration of the other parent. Besides being neglected in literature, they are often overlooked in the chaos that follows the death and incarceration of both parents and they feel alone, lost and invisible. Far from being distant spectators, many of these children were actually in the home when the homicide occurred and may have witnessed it or found the body of their parent (Harlon et al., 2016; Ifeanyichukwu et al., 2017; Loius \& Johnson, 2017). As a result, they may not only have to deal with the trauma of death by homicide but may be haunted by the sights and sounds that occurred during the incident including the mutilation of their mother's body or the "blank, evil, and frightening look in their father's eye immediately after he committed the homicide" (Loius \& Johnson, 2017:36). They may also be there when their father or mother is being arrested and taken away by the police. As bystanders, they may also witness the reactions of family members to the death notification. The varying gruesome experiences that the children are susceptible to in the event of domestic homicide and apprehension of their parents and the significant effect that it can have on their development and social life is the main concern of this study. In particular, the study will examine the psychosocial effects of domestic violence and homicide experiences on surviving children; and evolve an ideal psychosocial management that can safeguard the children from degenerating into social menace and improve their prosocial behaviours.

\section{Theoretical Orientation}

The purpose of this study which is to examine psychosocial effects of domestic homicide on children survivors makes it imperative for the adoption of a dual directional theoretical approach. Therefore, theoretical orientation for this research is taken from a theory rooted in psychology (attachment), and a sociological theory (social disorganisation). The adoption of these two theories is by no means an indication that there are no other relevant theories in the two fields that equally provide such theoretical depth to the study.

\section{Attachment theory:}

This theory looks at the importance of the developing brain on emotions and behaviours throughout the lifespan of a person (Schaefer, 2011). One of the pioneers of attachment theory is John Bowlby. His contributions, are rooted in psychodynamic thought, and include his works in attachment (1969), separation (1973), and loss (1980) (Robbins, Chatterjee, \& Canda, 2012). "Bowlby emphasised that attachment behaviour is regarded as a class of social behaviour of an importance equivalent to that of mating behaviour and parental behaviour" (Robbins et al., 2012:36). They went further to discuss how attachment 
occurs by the end of the first year for nearly all children, and the absence of attachment can lead to symptoms of serious developmental problems. Attachment provides a useful lens to enhance the understanding of domestic violence and the impact this has on the development of children because it gives the ability to understand the importance of the relationship, the attachment, and the effect that an insecure attachment can have on the relationship (Yamawaki, Ochoa-Shipp, Pulsipher, Harlos, \& Swindler, 2012). A child, who experiences this type of trauma at a young age, will not have an appropriately developed brain (Richards, 2011). This idea suggests that there will be significant differences between the brain of child who has grown up or is currently growing up in a loving, supportive, and caring environment, and the brain of a child who is witnessing domestic violence within their family system, causing them to experience constant fear and inconsistency; hence the inability to grow and thrive.

Attachment Theory suggests that an assaultive male's violent outbursts may be a form of protest behaviour directed at his attachment figure that may have rejected him and/or precipitated by perceived threats of separation or abandonment. (Robbins, Chatterjee \& Canda, 2012) Thus, the central features of a fearful attachment pattern are anxiety and anger (Keeling \& Van Wormer, 2011). Early life separation and loss were strongly correlated with adult domestic violence perpetration as well as exposure to parental violence, validating that insecure attachment style is related to the dis-regulation of the negative flow of emotions in intimate relationships (Moylan, Herrenkohl, Sousa, Tajima, Herrenkohl \& Russo, 2009). In addition, this theory offers a better understanding of the role of caregiver and child, and therefore will provide the theoretical framework guiding this study.

\section{Social Disorganisation:}

This theory has helped in the understanding of the dynamics and effects of neighbourhoods characteristics on criminal and delinquent behaviours that occur in public (Barnett \& Mencken, 2002; Kubrin \& Weitzer, 2003). In recent times, researchers have used social disorganisation theory in order to have a more complete understanding of the structural factors that may put individuals at risk for more private crimes, such as domestic violence (Emery, Jolley, \& Wu, 2011; Wright, 2011; Wright \& Benson, 2011). Social disorganisation theory is a consensus theory, whereby social order, social stability, and social integration occur as a result of common norms and values among members. The theory posits that the less cohesion, solidarity, and integration within members of a society or social group, the greater the rate of criminal and delinquent behaviour; whereas socially organised areas are effectively enforcing informal social controls and have lower rates of criminal and delinquent behaviours (Sampson \& Groves, 1989; Akers \& Sellers, 2009). The key role of a family as a social unit to foster cohesion cannot be achieved in a chaotic setting of domestic violence. Children that are offspring of such families hardly contribute positively to the cohesion, solidarity and integration of a society (Richards, 2011; Danies, Evans, \& DiLillo, 2016; Loius \& Johnson, 2017).

The main premise of social disorganization theory is that crime and delinquency result from a breakdown in structural and institutionalized social controls, or informal social controls (Sampson, 2012; Shaw \& McKay, [1942]1969). Informal social controls are regulated by members of a community and in a disorganised community these controls are not present, therefore, crime and delinquency flourish (Sampson, 2012; Shaw \& McKay, [1942]1969). This theory attempts to link violence in the family to the broader social environment. This includes the culture, the formal and informal social networks of the family, the closer family setting and circumstances, and the family history. This type of framework sets up a basis for a risk-theory of domestic assault based on the given criteria. In Nigeria, similar to other African countries, the beating of wives and children is perceived to be a necessary form of discipline (Aihie, 2016). Therefore, in beating their children parents believe they are instilling discipline in them, much the same way as in husbands beating their wives, who are regarded like children to be prone to indiscipline which must be curbed. This is especially so when the woman is economically dependent on the man (Abayomi, 2014).

\section{Synthesis:}

The attachment theory exposes the individual risk factors that may increase the odds of experiencing or perpetrating domestic violence. As postulated by the theory, one of the most common risk factors for domestic violence is experiencing or witnessing violence in one's family of origin. Several studies conducted to examine risk factors that increase the risk of domestic violence indicate that those that witnessed violence as a child between parents or guardians have an increased risk of being victims in their future intimate relationships. From the social disorganisation angle too, researchers have posited that structural-level factors are part of a larger model of violence examining the interrelationships between the individual, family, social-structural, and sociocultural levels. For example, the increase in the level of domestic homicide in Nigeria in recent times as against the traditional era has been attributed to specific breakdown at the structural level (Adebayo \& Kolawole, 2013; Abayomi, 2014; Aihie, 2016). The social control mechanisms that used to prevail in the time past have been systematically reduced by different factors, while the family structure has equally changed over time. Therefore, a combination of the psychological and sociological theories is adequate to effectively explain the individual and structural dimensions to the problem of domestic homicide and the effect it will have on the children.

\section{Research Methods and Data \\ Research Sites and Settings}

The research setting for this study includes three purposively selected prisons in Lagos State who provides accommodation for convicts and awaiting trial inmates of 
domestic homicide. The selection of the prisons was based on security level, geographic proximity and provision for convicts and awaiting trial inmates of spousal homicide. The sampling frame for this research consists of male and female maximum and medium security prisoners living in celled housing units in Kirikiri Maximum Prison, Kirikiri Female Prisons and Ikoyi Prison. In addition, two government agencies that work for the prosecution and control of domestic violence and homicide, Office of Public Defender and Directorate of Public Prosecution both in Lagos State were included in the study. The officials of the Welfare Unit of the Office of Public Defender and Prosecution officers of the Directorate of Public Prosecution were engaged to provide key information for the study. Finally, child psychologists resident in the University College Hospital, Ibadan were also included in the study.

\section{Data}

The site selection and sampling strategies employed for this study were designed to gather data from respondents who are both comparable to and distinct from one another in ways believed to be relevant to experiences in events leading to the killing of their spouse. The same goes for officials of Office of Public Defender, Directorate of Public Prosecution, Lagos State and University College Hospital, Ibadan. Data for this study consist primarily of in-person interview data collected during April and June of 2017; interview data were supplemented with official data on demographic and sentence-related characteristics and field notes taken throughout the duration of the study. All interviews were strictly confidential; pseudonyms are used throughout this article to refer to participants. The participation rate for the study was high (86 percent), with only three respondents declining to be interviewed. The total sample for this study is 18 prisoners (convicts and awaiting trial inmates), with 12 males and six females; four welfare officials of Office of Public Defender; three prosecuting officers of Directorate of Public Prosecution and two child psychologists with the University College Hospital. Audio recording were not allowed during the interview for prison inmates, therefore notes of the proceeding were taken down by a research assistant. However, audio recording was permitted for interviews with key informants. Interviews averaged forty-five minutes. The shortest interview was eight minutes and the longest lasted one hour fifteen minutes. The variability in interview duration was a product of the semi-structural nature of the interviews.

For the offenders of domestic homicide, each interview started with open-ended questions designed to elicit information about their marriage experiences without specifically referencing domestic violence or homicide. The goal of this segment of the interview was to elicit general thoughts and feelings about family life without specifically broaching the topic of homicide. The next sets of questions were more tailored towards domestic violence. However, interviews with the experts took a different pattern as direct questions were asked from the onset after intimating them with the purpose of the study. In all, 18 offenders of domestic homicide in the selected prisons, and nine key informants provided primary data for this study, while secondary data were collected from the Office of Public Defender, Directorate of Public Prosecution and selected prisons.

\section{Method of analysis}

Data analysis followed the iterative process that often characterises grounded theory in particular, and qualitative research more generally (Emerson, Fretz, \& Shaw, 1995). During data collection, extensive field notes on any interactions and observations relevant to the study of domestic violence and abuse were taken. After data collection was concluded, content analysis was done with the use of a qualitative software program (NVivo) was deployed. Content analysis has to do with the probing of content and themes of text to uncover both definitions contained in the text and those that emerge through the analysis (Krippendorff, 2012). Open coding was used to identify themes apparent in the respondents' narratives through line-by-line analysis. Once initial memos were written and links between themes became clearer, we returned to the full body of data to begin focused coding. Focused coding helped in ensuring that the themes that emerged from the initial subset of the data were both relevant to and appropriately configured for the full set of data. Focused coding followed a similar line-by-line process to that of open coding, but applied the specific codes that had been identified as important to the theoretical framework.

\section{Research Findings \\ Sociodemographic characteristics of respondents}

Though the sample of the study was 18, the sociodemographic characteristics of the respondents still showed considerable diversity. Data on age, education, and status in the prison were obtained from official report while the rest were obtained from offender self-report. Only six of the respondents were females while the remaining 12 were males. The lopsidedness in gender distribution is as a result of higher number of males in the study population and the willingness of more males to partake in the study. The respondents were youthful though only two of them were below age 30 , while majority of them (13) were between age $30-40$ and only three were above 40 years old. All of them are educated with the least number (2) having secondary education while the rest of them (16) are at least graduates of higher institutions. In respect of the status of the respondents in the prisons, trials of majority of them are still ongoing while only four of them (two of whom are condemned to death) are convicted. Majority of them are of Yoruba ethnic affiliation (8), Christian religion (10) and self-employed (12). The interviews were conducted primarily in English (and occasionally in Pidgin English and Yoruba). 


\section{Offenders'childhood experience of domestic violence}

In their growing up years, all the inmates of the selected prisons who are convicts and awaiting trial prisoners described an array of experiences of domestic violence involving their parents and guardians. Sixteen of the 18 respondents expressed that they had abusive childhood where parents and guardians subjected them to 'excessive disciplinary punishments' like 'beating' 'flogging' 'slapping' 'kicks' 'hitting on the head' 'throwing items at me' 'pushing me violently' 'hitting with sticks and other objects.' Majority of them noted that they grew up with such perception that anytime they go wrong or engage in wrongful behaviour, such disciplinary measures would automatically be meted out on them as penalty. Eight of them described a more intense abuse like 'being locked out to sleep outside their homes,' 'being hit with iron and other dangerous materials that saw them spilling blood' 'being locked up in a room for hours' 'denial of food and drinks as punishment for a day or more' 'hiring third party to beat me up'. Tayo, a 32 year old who is undergoing trial for strangling his wife in her sleep to death volunteered:

I grew up with the belief that it is normal to hit and kick a child as this was the treatment that I underwent in my childhood. In fact, it got to an extent that if I am not beaten for doing something wrong, I get worried or fearful as my father's silence can be more dangerous. It is only after he had beaten me that I will be rest assured that I have paid my debt for that wrongdoing...

In respect of the respondents' witnesses of violent encounters between their parents, 13 of them expressed that they had witnessed frequent occurrences of violent altercations between their parents, 11 added that they had witnessed their parents' fight with other people in their growing up years. The respondents described the fights between their parents as involving fisticuffs, throwing of items to each other, hitting each other with dangerous items, destroying properties, and engaging in wrestling bouts. According to them, these events are normally 'disturbing', 'saddening' 'embarrassing' to them when they were young. They stated that they reacted by crying, running to their room and locking up themselves, covering their eyes in shame and fear, running out of the house to call for help, making phone calls to relatives, and making attempt to separate them.

\section{Perception of violence and abuse as adult:}

Considering the growing up years of the respondents in which they experienced violence and abuse, they were asked about their perception of violence and abuse when they attained adulthood. An overwhelming majority of them perceives violence and abuse as not good but inevitable. They opined that there should be discipline if 'one wants to assert authority as a man, father and husband' 'one needs to slap a woman to order sometimes' 'it is almost impossible to have a violent-free relationship in marriage.' One of them provided more details: ...well I will not call it violence, but it's just an occasional strike that is meant to express one's strong disapproval to a situation. After all the Bible also support that such means of correction is required for children. It is indeed very difficult to gain the respect and fear of a woman without you using it (violence) once in a while. However, it shouldn't be every time, otherwise it will lose its potency...

\section{Adetunji/39/Kirikiri Maximum}

Adetunji went further to state that he got his idea from his late father who told him that a man should be ready to be violent in order to be respected by his wife, and that any man that fails to employ violence when confronted by his wife, is a weakling. Generally, the respondents perceive violence as being inevitable and useful if applied moderately in relationship between parents and children as well as between husband and wife. They provided reasons that are closely related to the position of Adetunji quoted above. They opined that it is only when it goes wrong that it might land them in the kind of trouble they found themselves. Kazeem pointed out that 'it is used to train children that become president (successful) and it is also used for wives that end up staying married with a man for 50 years and more.' Ironically, the female respondents also corroborated the position of the males by implying that 'reasonable measure of violence' is tolerable in a marital relationship. All six of them said they would have remained tolerant if their husbands were not too aggressive and consistent in resorting to violence at every given opportunity.

\section{Children's Exposure to Domestic Violence and Homicide} Consequent upon the admission by all the respondents that there were varying degrees of violence in their families prior to the demise of one of the spouses, the study moved to examine the exposure of their children to such violent experiences. They were requested to provide information on whether they normally take note of the presence of their children when they engage in arguments and violence. This query was relevant to 14 of the respondents (with four of the six females) that have children who lived with them.

Eleven of the 14 respondents that had children living with them admitted that their children had been present 'occasionally' when they had violent encounters with their wives. They stated that it is difficult for them to remember the children whenever they were angry to the level of engaging in fights with their spouses. Teslim, (a 46 years old and father of three children, condemned to death in Kirikiri Maximum Prison) who bathed his wife in acid for infidelity wondered:

Is it possible to be asking the children under such condition of anger to leave the house that we want to fight (he laughed)? Don't forget that it is hot arguments that often lead to serious fight. The only care that I often take is to ensure the children are not injured during the process of fighting with 
their mother, because she is fond of throwing things at me.

The rest of the 10 respondents in this category described how their children had witnessed the violent encounters with their wives. Some of them remarked that they had intended to exercise caution but their accommodation space was too small to keep their children at a healthy distance from the scene of the fight. In some instances, respondents stated that their children peeped through key holes and other available channels while they engaged in arguments and fights with their spouses. However, only three of the respondents expressed that they are oblivious to the risk involved in the children witnessing such violence. They all implied that they thought it is even good for the children to know and learn about marital problems so as to avoid falling prey in the future.

Psychological Effects on Spousal Violence on Children: As the majority of the offenders stated that their children often witnessed the violent encounters that they had with their spouses before the deadly incidence, the study moved to examine the psychological effect of these events on the children. One of the psychologists, Mr. Osahon volunteered: 'it affects children in so many ways. In the way they see life especially when it happens in their formative years. It affects their output to life'.

In a more comprehensive explanation of the effects, Mr Olagunju offered:

Children need a rounded picture of their parents in order to resolve their own inner identity struggles. When a father, for example, has no redeeming qualities, the child's self-image can be damaged because of the conflict inherent in trying to identify with the father. "If daddy is bad, then half of me must be bad because half of me come from daddy." These kinds of fears are common.

$\mathrm{He}$ went further to state that children that witnessed spousal violence often worry that they may inherit the badness or sickness of the perpetrator. That they will fear that they will end up like the parent who was killed or even the one that killed the other partner, or even that the perpetrator will come back to kill them too. volunteered:

In a similar explanation of the effect, Mr Adeniyi

The apprehensions of children that suffer such experience are not without merit, it has been well researched. The effect can be endless depending on the nature of such child. Some children may not forget so easily and can develop PTSD, anxiety and some may even hate marriage- see it as a deadly thing, some mental illness. Such children also have difficulties with attachment.

The key informants all pointed out the experience of the children in family violence have varying negative consequences on their developmental process.

\section{Children witnessing Domestic Homicide:}

Only two of the 14 offenders stated that their children were present during the final violence that led to the death of their spouse. One of the two pointed out that the child that witnessed it was less than two years at the time. However, the other respondent said he had three children (with the youngest being seven years old) who were present at the time he 'accidentally' killed his wife:

...it wasn't my intention (to kill her), I thought it will be just one of those quarrels we always have only for her to collapse. The children joined me to help her but by the time we got to the hospital, she was pronounced dead...

The rest of the 12 gave different reasons why their children were not around at the incident of homicide. Out of the 12 of them, four (three males and a female) stated that they ensured that their children were not around at home because their attacks were premeditated. Meanwhile, the other eight of them said that the absence of their children were mere coincidence.

In line with the responses of the participants, the child psychologists were requested to provide informed opinion as regards the effects that the presence of the children at the site of their parent's demise may have on them. Mr Olagunju volunteered:

...if children should witness the murder of a parent, then there will be psychiatric consequences like trauma. There may be both short-term and long-term effects. On the shortterm, it can make some children to be in a state of shock or numbness over a reasonable period of time. They will feel sad, depressed, lonely and angry. Don't forget the fact that in such situation, they will lose both parents at the same time. On one hand, they are victim-survivor, and on the other, they are offspring of a murderer. So the two roles will have psychological impacts on them on the long run...

Other psychologists corroborated the position of Olagunju as they provided different short- and long-term effects of witnessing such events. Mr Adeniyi pointed out that 'some of their difficulties may not just be related to the murder but the level of disruption that may have hit their young lives.' Mr Osahon stated in this direction:

...there are multifaceted problems that can emanate. For instance, if their home is sealed off as crime scene, they may suffer want of familiar clothes or other personal effects. If they have access to their original home, it is like an empty shell, filled with haunting reminders and echoes of the person who is now dead...they may also lose their neighbourhood, school, and friends in the process, so they have to adjust quickly to unfamiliar environment. 
In response to a query on peculiar problems such children can face in Nigeria, Mr Olagunju offered:

It affects their general overview of life especially because members of our society are good at stigmatizing. The child/children will feel abandoned and this is because apart from passing judgment on the killer husband/wife, the government tend to forget so easily about the children except there's a strong follow up from and welfare section like NGO's e.t.c It can affect their education and all other aspect of their life(s) if they are not properly handled i.e. undergo therapy in the early stage of the incident.

Based on the issue raised by the psychologists that Nigerian government do not support children that are offspring of such violent family, this study included officials of the Welfare Units of Office of Public Defender and Directorate of Public Prosecution in the research, in order to provide information on the intervention policy of the government for such families.

\section{Post-homicide Care and Support System for Children:}

The study sought to find out the care and support systems that are available for such children considering the psychosocial risks that they faced aftermath of them losing both parents. The officials of Office of Public Defender and Directorate of Public Prosecution were engaged to provide the information. However, interviews with the officials revealed that there are no concrete provisions on the part of the agencies and on behalf of the government to ensure that a support system is established for the children. All the agencies do is to hand over the children to the families of either the offender or victim.

According to one of the welfare officers of OPD, Mr Chukwujekwu 'the government interferes and most times the children are handed over to responsible family members.' However, another official of OPD (Mr. Sowole) added that 'we sometimes provide psychosocial counseling, while the OPD source for sponsors and most times the government interferes by giving free education'. Officials of OPP however stated that it is not 'in their functions to provide care and support measures for children of such parents'. According to one of the officials, 'we only ensure that justice is served and hand over children to the families of the deceased or incarcerated for care.'

\section{Required Psychosocial Interventions Needed for the Children:}

Though the government agencies included in the study volunteered that government do not have concrete policies in place to support the children-survivors of domestic homicide, the study still requested the key informants to provide information as regards the psychosocial interventions requirements for such children. One of the OPD officials offered:

Stigmatization is the major problem and this is because of the way our society is. If the children are not properly monitored they can become street children as a way of trying to source for livelihood for themselves and the girls can even suffer sexual abuse in the course of roaming about which can eventually make them to start prostituting.

\section{Mr Sowole/OPD Welfare Unit/Lagos}

Ironically, one of the officials of OPP (Mr. Ahmed) believes the government needs to be more involved; 'they (the children) should go for therapy. The government should be more involved, they should assist with funds \& even psychologists or people who will help to counsel in such situations.' Mr. Olagunju also corroborated the opinion of Mr Ahmed as regards the need for therapy, and also added:

They need to see a therapist, whether it happened in their presence or not. Do not just let them just go or just take them to welfare homes. They must talk about the things they saw or heard, it is very important they talk about it.

The rest of the key informants aligned with the position above that therapy are required as a necessary psychological intervention, while adequate reintegration measures into the society, devoid of stigmatisation should be in place for the children.

\section{Discussion of Findings}

The present study has shown that early exposure to parental violence in the family of origin is associated with intimate partner violence and marital violence. Childhood psychological or physical abuse by parents represents negative early interpersonal life events that may have a developmental impact on the capacity to assume appropriate adult roles in close relationships (Godbout et al., 2009; Adebayo \& Kolawole, 2013; Naughton et al., 2017). The study found that perpetrators of spousal homicide had childhood experience of abuse and witnessing parental violence. This shaped their developmental stages and makes them to perceive violence as an integral part of intimate relationship. This finding is in consonance with that of Danies, Evans, \& DiLillo (2016), who conducted a comprehensive empirical review of the risk markers in husband-to-wife violence, including 52 case comparison studies and more than 97 potential correlates of intimate partner violence. They found that the most consistent factor of intimate partner violence was experiencing or witnessing parental violence as a child.

The study also found that the perpetrators of domestic violence and spousal homicide are either not aware of the psychological effects it has on children or are unmindful of children's presence when they perpetrate violent acts. This negligence has been found to have both short term and long term effects on the children that experienced such level of violence. Some of the short terms effects are PTSD symptoms, physical health problems, psychosomatic issues and sleep disturbances; while some of 
the long term effects are self-image problems, difficulties with attachment, inner identity struggles, loyalty conflicts, fears and enduring trauma. A growing body of research shows that domestically abusive males are far more likely to have been exposed to family violence as children, as compared to nonviolent males, males who are unhappy in their relationship, or male perpetrators of other crimes, suggesting that witnessing and experiencing parental violence are specific precursor of spousal violence (Robbins et al., 2012; Aihie, 2016; Loius \& Johnson, 2017).

The findings of the study on the effects of spousal homicide on children-survivors bother on the need for intervention to care and support the children so that they do not suffer identified psychological effects. This present study reveals that the Nigerian government is only alive to its penal responsibility in cases of spousal homicide, but not doing enough for the children-survivors. The studies reviewed in this research have pointed out the psychological and sociological effects that such children are exposed to (Emery et al., 2011; Richards, 2011; Danies et al., 2016; Loius \& Johnson 2017), therefore, the lukewarm attention paid by the government and other stakeholders to the welfare of the children may be partly responsible for the growth in domestic homicide in the country.

Based on the findings of this study, the key areas of intervention needs for the children-survivors are: psychological therapy, counselling, funds to cover schooling and other welfare, and protection from stigmatisation. According to Loius \& Johnson (2017), the recovery of survivor-children that are adult is often complicated by estranged family relationships, emotional impasses, and conflict between victim's and perpetrator's extended families. Irresolvable binds contribute to chronic conditions which include loneliness, anger, and feelings of betrayal. Domestic homicide divides the loyalties within a person, as well as between family members.

\section{Conclusion}

The trauma from domestic homicide is enduring and causes long-range changes in the way people function. In Nigeria, for the children who remain, many of them are left to manage on their own. However, this study, in agreement with existing literature upholds that there is need for the children to be supported all the way from the time of the homicide, through the trial and conviction of the parent that perpetrated the crime, and even after through their developmental stages.

This study raises the need for treatment of violent child trauma for survivors of domestic violence and homicide; couples' therapy for violent spouses; treatment for parent-child relationship, especially for children being abused by their parents; domestic violence perpetrator prevention programming; relief of suffering from domestic violence, abuse and loss of parents; resolution of trauma symptoms; and, provision of supportive environment. In addition, as part of prosecution process, it is imperative for relevant agencies to first clarify the cognitive or emotional distortions about the homicide as it must have affected the children-survivor. This is based on the relevance of such measures to enable effective strategies to check the growth of the prevalence of domestic homicide in Nigeria. As if left unaddressed, the generational cycle of abuse will continue to thrive while minor forms of aggression are likely to escalate into more severe or life-threatening violence.

It is indeed evident that based on the prevalence of domestic homicide in Nigeria in recent times, the findings of the study supports the importance of social policies informed by well-funded research that will allow better education and prevention, creation of efficient training programs for law enforcement officials, health care providers, and the general population to stop the generational cycle of abuse.

\section{References}

Abayomi, A. (2014). Sociological implications of domestic violence on children's development in Nigeria. Journal of African Studies and Development, 6(1), 813.

Adebayo, A., \& Kolawole, T. (2013). Domestic Violence and Death: Women as Endangered Gender in Nigeria. American Journal of Sociological Research, 3(3), 53-60.

Aihie, O. (2016). Prevalence of Domestic Violence in Nigeria: Implication for Counselling. Edo Journal of Counseling, 2(1), 1-8.

Akers, R. L., \& Sellers, C. S. (2009). Criminological theories: Introduction, evaluation, and application. New York, NY: Oxford University Press.

Barnett, C., \& Mencken, F. C. (2002). Social disorganization theory and the contextual nature of crime in nonmetropolitan counties. Rural Sociology, 67(3), 372-393.

Danies, C., Evans, S., \& DiLillo, D. (2016). Exposure to Domestic Violence: A Meta-Analysis of Child and Adolescent Outcomes. Aggression and Violent Behavior, 34(2), 212-221.

Emerson, R., Fretz, R., \& Shaw, L. (1995). Writing Ethnographic Fieldnotes. Chicago, IL: University of Chicago Press.

Emery, C. R., Jolley, J. M., \& Wu, S. (2011). Desistance from intimate partner violence: the role of legal cynicism, collective efficacy, and social disorganization in Chicago neighborhoods. American Journal of Community Psychology, 48(3-4), 373-383.

Godbout, N., Dutton, D., Lussier, Y., \& Sabourin, S. (2009). Early exposure to violence, domestic violence, attachment representations, and marital adjustment. Personal Relationships, 16, 365-384.

Harlon, R., Brook, M., Demery, J., \& Cunningham, M. (2016). Domestic Homicide: Neuropsychological Profiles of Murderers Who Kill Family Members and Intimate Partners. Journal of Forensic Sciences, 61(1), 163-170.

Ifeanyichukwu, O., Christopher, P., \& Kizito, D. (2017). The Emerging Trend in Culture of Domestic 
Violence in Nigeria: Causes, Theoretical Assumptions and Implications. Research Journal of Humanities, Legal Studies \& International Development, 2(1), 53-63.

Keeling, J., \& Van Wormer, K. (2011). Social worker interventions in situations of domestic violence: What we can learn from our survivors' personal narratives? British Journal of Social Work, 42, 13541370.

Krippendorff, K. (2012). Content Analysis: An Interoduction to its Methodology (3rd ed.). CA: Sage: Thousand Oaks.

Kubrin, C. E., \& Weitzer, R. . (2003a). New directions in social disorganization theory. Journal of Research in Crime and Delinquency 40(4), 374-402.

Loius, S., \& Johnson, E. (2017). How mothers perceive their own domestic violence victimization and how it impacts their children. Journal of Child Custody, 14(1), 34-48

Moylan, C., Herrenkohl, T., Sousa, C., Tajima, E., Herrenkohl, R., \& Russo, R. (2009). The effect of child abuse and exposure to domestic violence on adolescent internalising and externalising behaviour problems. Journal of Family Violence, 25, 53-63.

Naughton, C., O'Donnell, A., \& Muldoon, O. (2017). Exposure to domestic violence and abuse: Evidence of distinct physical and psychological dimensions. Journal of Interpersonal Violence, 28(2), 341-352.

Richards, K. (2011). Children's exposure to domestic violence in Australia. Trends and Issues in Crime and Criminal Justice (419), 1-5.
Robbins, S., Chatterjee, P., \& Canda, E. (2012). Contemporary human behaviour theory: a clinical perspective for social work. Upper Saddle River, NJ: Allyn and Bacon.

Sampson, R. J. (2012). Great American city: Chicago and the enduring neighborhood effect. Chicago, IL: The University of Chicago Press.

Sampson, R. J., \& Groves, W. B. (1989). Community structure and crime: Testing social-disorganization theory. American Journal of Sociology, 94(4), 774802.

Schaefer, C. (2011). Foundations of play therapy. New Jersey: John Wiley and Sons, Inc.

Shaw, C. R., \& McKay, H. D. (1969). Juvenile Delinquency and Urban Areas. Chicago, IL: University of Chicago Press.

The Guardian. (2017, August 2). Lagos records 574 cases of domestic violence, sexual harassment. Retrieved $\mathrm{S}$ e $\mathrm{p} \mathrm{t} \mathrm{e} \mathrm{m} \mathrm{b} \mathrm{e} \mathrm{r} \mathrm{4,} 2017$, f r o m https://guardian.ng/news/lagos-records-574cases-of-domestic-violence-sexual-harassment

Wright, E. (2011). Neighbourhoods and intimate partner violence. E1 Paso, Texas: LFB Scholarly Publishing LLC.

Wright, E. M., \& Benson, M. L. (2011). Clarifying the effects of neighborhood context on violence "behind closed doors." Justice Quarterly, 28 (5), 775798.

Yamawaki, N., Ochoa-Shipp, M., Pulsipher, C., Harlos, A., \& Swindler, S. (2012). Perceptions of domestic violence: The effects of domestic violence myths, victim's relationship with her abuser, and the decision to return to her abuser. Journal of Interpersonal Violence, 27 (16), 3185-3212. 